\title{
ENSAIO DE CARACTERIZAÇÃO ESTRATIGRÁFICA DO CRETÁCEO NO ESTADO DE SÃO PAULO: GRUPO BAURU
}

\author{
PAULO C. SOARES*, PAULO M.B. LANDIM*, \\ VICENTE J. FULFARO* e AGOSTINHO F. SOBREIRO NETO**
}

\begin{abstract}
Mapping survey over $135,000 \mathrm{~km}^{2}$ in the State of São Paulo, made by Departamento de Águas e Energia Elétrica do Estado de São Paulo (DAEE) in cooperation with other organisations, allowed the stratigraphical characterization of the Cretaceous rocks younger than Serra Geral Formation (lower Cretaceous) in that region. Due to the regional stratigraphical analysis of these sediments is proposed for them the term Bauru Group which is constituted by the following four Formations:

1) Caiua Formation: fine to medium sandstone with regular to good sorting and purple color, bearing large cross stratification; occurrence limited to the Pontal do Paranapanema region; it is in unconformity over basalts of the Serra Geral Formation.

2) Santo Anastácio Formation: very fine to medium sandstone, red to purple colors; low angle cross stratifications to horizontal bedding, with rare mudstone beds intercalated; occurrence mainly in southwestern portion of São Paulo State; gradational over Caiuá Formation and with discordance over basalts.

3) Adamantina Formation: a) Araçatuba lithofacies - thick beds of mudstones, dark brown to greenish grey colors, with variations to siltstones and claystones; restricted occurrence in the southwestern portion of São Paulo State and wide one in the western and northwestern portion of the State; overlying Santo Anastácio Formation and Serra Geral Formation; $b$ ) Taciba lithofacies - beds of very fine to fine sandstones, with small to large size cross stratifications, intercalated with beds of reddish to brownish sandy mudstones; incipient lamination and sandstone lens; wide occurrence from south to the north of the State over Santo Anastácio Formation (south), Araçatuba lithofacies (west and northwest) and basalts (northeast); c) Ubirajara Formation - coarser sandstones than that one, from Taciba lithofacies, textural and mineralogical imatures, with occurrence in mid-east portion of the State over basalts, lateral gradation to Taciba lithofacies toward west and north.

4) Marilia Formation: coarse to conglomeratic sandstones plentiful of calciferous cement and nodules; occurrence in the wathersheds of the principal drainages in São Paulo State inland.

The contact relationship and regional distribution of the stratigraphic unities suggest a partial contemporaneous deposition in a complex fluvial system, with regional and chronological variations in the clastic affluence, in the climatic characteristics, in the subsidence ratio and in the marginal areas uplift rate.
\end{abstract}

INTRODUÇÃo Desde 1974, o Departamento de Águas e Énergia Elétrica do Estado de São Paulo (DAEE) vem realizando por meio de convênios com a UNESP, a USP e o IPT levantamentos geológicos sistemáticos no Estado. Nos trabalhos efetuados nas regiðes 6, Ribeirão Preto (Soares et al., 1972), 7, 8 e 9, São José do Rio Preto, Bauru e Araçatuba (Suguio et al., 1977); e 10 e 11, Presidente Prudente e Marilia (Soares et al., 1979), um dos objetivos alcançados foi a divisão da então considerada Formaçăo Bauru em unidades mapeáveis na escala 1:250.000, embora com critérios variando de uma regiáo para outra. Tais unidades designadas informalmente membros ou litofácies ou mesmo fácies puderam ser reconhecidas em trabalhos de campo posteriores objetivando a integração aqui apresentada.

O grés de Bauru, conforme foi definido por Gonzaga de Campos em 1905, tem sido objeto de intensas e detalhadas investigaçð̃es mas, dadas a extensão de sua ocorrência e a ausência de horizontes litoestratigráficos ou bioestratigráficos, não existe ainda uma divisão em unidades caracterizáveis regionalmente dentro de uma classificaçâo estratigráfica formal. Daí a razão porque, face d̀ existência das citadas observaçôes de campo por toda a área de afloramento no Estado de São Paulo dessa unidade estratigráfica, é aqui apresentada uma proposta de subdivisão da mesma.

DIVISÃO ESTRATIGRÁFICA Os diversos trabalhos escritos sobre o Bauru consideraram-no Série (Freitas, 1955), Grupo (Almeida e Barbosa, 1953; Barbosa et al., 1967) ou Formaçåo (Washburne, 1930; Arid, 1967; Suguio, 1973; Mezzalira, 1974; e outros). Em geral, esses trabalhos trataram de temas específicos, como sedimentologia (Freitas, 1955; Suguio, 1973; Coimbra, 1976; e outros), paleontologia (Price, 1950, 1953; Arid e Vizotto, 1965; e outros), ou estudos regionais (Barbosa 
et al., 1967 e 1970; Arid, 1967; Suárez, 1975; Brandt Neto, 1977; e outros), ou, ainda, trabalhos com enfoque maior na distribuição vertical das litologias (Mezzalira, 1974).

Diversos autores procuraram definir o relacionamento estratigráfico entre as várias fácies ou conjuntos de fácies mas, tendo em vista a não-ocorrência em toda a bacia de deposição dessas diferentes unidades e as complexas relaçðes de contato, não conseguiram concluir por uma sistemática litoestratigráfica.

Após esses trabalhos relacionados, Soares et al., (1979) mapearam a região em que se encontra o mais completo registro do Cretáceo médio e superior do Estado de São Paulo, o Sudoeste, caracterizando as diferentes unidades genéticas mapeáveis. Baseando-se nesse mapeamento e nos realizados por Soares et al. (1974) e Suguio et al. (1977), foi organizado o presente ensaio no qual é proposto que a Formação Bauru passe à categoria de Grupo Bauru constituído de quatro formaçð̃es que såo aqui definidas e caracterizadas: Formação Caiuá, Formação Santo Anastácio, Formaçăo Adamantina e Formação Marília (Fig. 1).

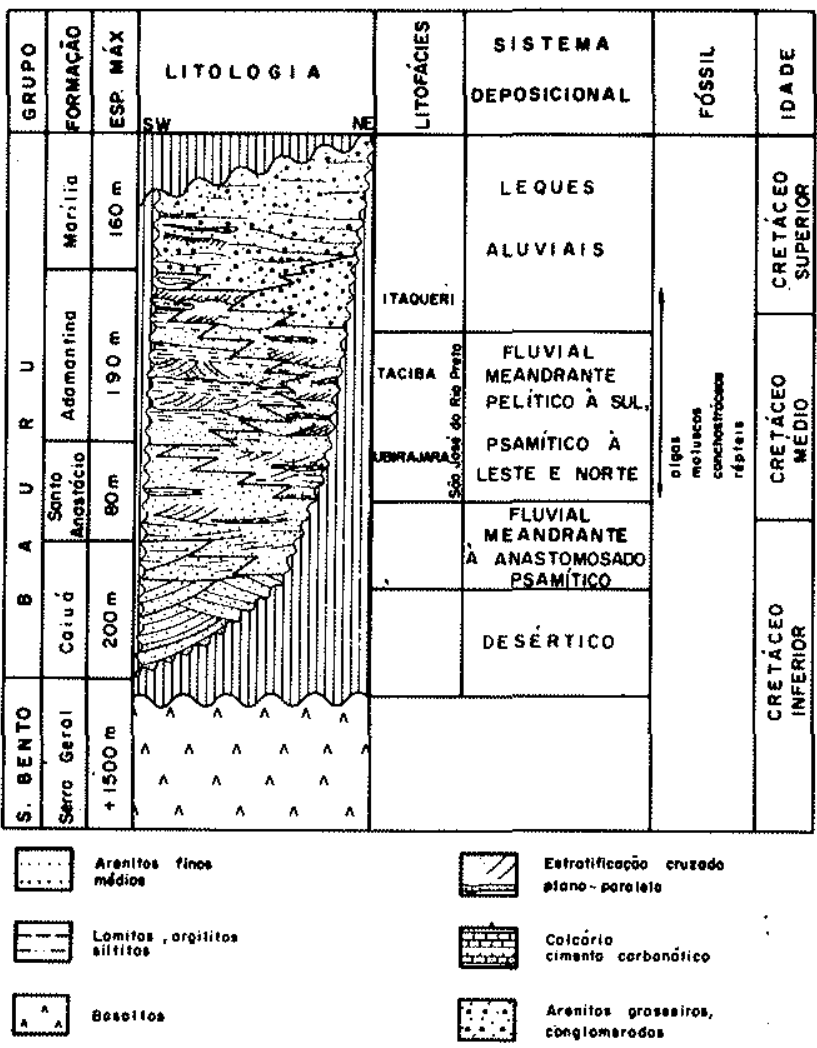

Figura 1 - Quadro estratigráfico do Grupo Bauru

FORMAÇÃO CAIUÁ Definição e características litológicas A Formaçăo Caiuá, apesar de definida há bastante tempo (Washburne, 1930), tem uma posiçăo estratigráfica discutível. Assim, após uma discussão que durou alguns anos sobre sua posição, se abaixo ou acima da considerada Formaço Bauru, tendo sido constatada a validade da primeira hipótese (Landim e Soares, 1976), resta ainda o problema de sua classificação estratigráfica. Veja a propósito que, segundo Schneider $e t a l$.
(1974), a mesma se acha encaixada como Formaça no Grupo Såo Bento. Propőe-se aqui que esta unidade seja incluída no Grupo Bauru tendo em vista as similaridades litológicas com as unidades que lhe sucedem.

A principal característica da Formação Caiuá é sua notável uniformidade litológica, representada por arenitos de muito finos a médios, com estratificação cruzada de grande porte. Os arenitos apresentam seleção boa nos níveis de estratificaçăo, variando entre lâminas de areia fina e lâminas de areia média e muito fina. Matriz lamítica é rara, inferior a $5 \%$. Ocasionalmente, ocorrem lâminas de arenito com teor elevado de matriz. Os gråos são de subarrendondados a bem arredondados com grau variável de esfericidade, envolvidos por uma película de limonita que fornece cor de vermelha-escura a arroxeada para a rocha. Muito provavelmente, essa limonita é o resultado da alteração de minerais de ferro (magnetita) existente na unidade. Os arenitos são quartzosos (quartzarenitos) embora o conteúdo em grãos de calcedônia e opala às vezes chegue a atingir $15 \%$.

Como estruturas sedimentares só tem sido observada estratificaçåo cruzada de grande porte, tangencial na base. Na maioria dos casos são côncavas em planta no sentido do mergulho das lâminas. $O$ azimute médio do mergulho é para oeste, aproximadamente, com boa persistência da direçâo.

Ocorrência e espessura A Formação Caiuá foi definida por Washburne (1930) na regiăo do Pontal do Paranapanema por suas exposiçōes nas barrancas do Rio Paraná em Porto Presidente Epitácio, no lado paulista. No Estado de São Paulo, as exposiçôes dessa unidade estão restritas a essa área. Sob outras unidades do Grupo Bauru tem sido encontrada em poucas perfuraçð̃es nessa região restringindo sua ocorrência a oeste de Pirapozinho e Presidente Prudente e sul de Panorama (Soares et al., 1979).

No Estado do Paraná, sua ocorrência em superfície cobre extensa área na região noroeste, tendu sido representada no mapa geológico do Paraná na edição de 1956. Apresenta aí as mesmas características que no Estado de São Paulo.

No Estado de Mato Grosso do Sul, regiåo sudeste, há também ocorrência extensiva, tendo sido mapeada apenas por Stein et al. (1979). Nos demais Estados do sul, não se tem notícia da ocorrência da Formação Caiuá.

A máxima espessura conhecida desta Formação é no noroeste do Paraná com cerca de $200 \mathrm{~m}$ no Morro dos Três Irmåos, reduzindo-se para norte e oeste.

Relaçós de contato $\mathrm{O}$ contato basal da Formação Caiúa se faz com os basaltos da Formaça Serra Geral. E discordante, embora não haja uma caracterizaç̃o adequada desse contato pois os afloramentos estão geralmente intemperizados. Tem sido admitido também um ciclo erosivo entre ambas as formaçסes (Soares e Landim, 1975). A presença de solo fóssil e a inexistência de brecha de topo de derrame no contato entre essas duas unidades foram verificadas em sondagens nas obras da barragem de Porto Primavera (Soares et al., 1979). Isso é uma indicação de que o transporte e a sedimentação de areias do Caiuá não estariam ocorrendo 
nos episódios finais do vulcanismo, havendo, sim, um hiato entre uma unidade e outra, com erosão e formação de solo. Desse modo, esses arenitos não estariam associados ao ambiente de deposição da Formação Botucatu.

Ambiente de deposiçao As características litologicas da Formação Caiuá, especialmente a homogeneidade textural e a estratificação cruzada de grande porte, com ausência de outras fácies, sugerem deposição eólica. Mesmo nos arenitos basais conserva-se essa homogeneidade litológica, com corpos de arenitos muito finos e médios bimodais e arenitos finos unimodais com boa seleção. Outras feiçðes, como estruturas deformacionais por rompimento de camadas e níveis de deflação, estão presentes indicando origem eólica. Além disso, a ausência de conglomerados, mesmo sobre a superfície do basalto, não indica sedimentação fluvial.

\section{FORMAÇÃO SANTO ANASTÁCIO' Definição e caracteristicas litológicas $\mathrm{O}$ nome Santo Anastácio} foi utilizado inicialmente por Soares e Landim (1975) como uma fácies da Formaçăo Bauru: a fácies de arenitos finos, situada na porção inferior daquela formaçăo. Posteriormente, em consequência do mapeamento realizado na regiåo do Pontal do Paranapanema, Landim e Soares (1976) caracterizaram essa fácies com estudos sedimentológicos e a designaram membro Santo Anastácio.

O nome foi dado à unidade porque as melhores $\mathrm{e}$ mais características exposiçð̃es são encontradas no vale do Rio Santo Anastácio, afluente do Rio Paraná na regiåo do Pontal do Paranapanema, Estado de São Paulo. Também é no leito desse rio, na estrada que, saindo de Presidente Venceslau, margeia o Rio Paraná, em direção ao Porto Castilho, que foi encontrado um afloramento do contato basal dessa unidade com a subjacente Formação Caiuá. Nas cabeceiras desse rio encontra-se o contato com a sobrejacente Formação Adamantina ou, ainda, a sul, na Rodovia da Integração entre Marabá Paulista e o Rio Santo Anastácio. Devido d̀ inexistência de exposições contínuas e raridade de afloramentos não foi possivel definir seçåo-tipo para essa unidade.

A Formação Santo Anastácio é constituída dominantemente de arenitos de granulação de muito fina a média, com pouca matriz, em geral inferior a $15 \%$. Os grãos, de tamanho médio, apresentam-se em parte arredondados, indicativos de uma contribuição a partir da Formação Caiuá, e de subarredondados a subangulares. Contêm uma elevada porcentagem, até $15 \%$, de grãos de opala e feldspato, e os grãos de quartzo apresentamse cobertos com uma película limonítica, o que confere aos arenitos uma cor marrom-avermelhada com pintas brancas. A seleção dos arenitos e de regular a boa, com pouca variaça textural, e localmente ocorre cimento calcífero, com concrecionamento do arenito e formaça de figuras irregulares e nódulos.

Os arenitos da formação Santo Anastácio são pobres em estruturas sedimentares, aparecendo em bancos, espessos de 2 a $3 \mathrm{~cm}$, maciços com incipiente estratificaçăo em cortes de estrada. A estratificação dominante é plano-paralela e a cruzada de baixo ângulo (de $5^{\circ}$ a $10^{\circ}$ ) planar tangencial na base; raramente apresen- ta-se com inclinação maior de $10^{\circ}$ ou em corpos acanalados.

Nos corpos tabulares com estratificaçåo plano-paralela ocorrem camadas descontínuas ou lentes de lamito marrom-avermelhado, maciço, intercalados em arenitos de muito finos a médios, lamíticos.

Ocorrência e espessura A Formação Santo Anastácio ocorre em superfície em estreita faixa no flanco norte do vale do Rio Paranapanema, contornando a região do Pontal, pelo Morro do Diabo e Planalto do Sul; tem maior expressão no vale do Rio Santo Anastácio com espessura da ordem de $80 \mathrm{~m}$ e no vale do Rio do Peixe e afluentes da margem sul com espessura em torno de 50$60 \mathrm{~m}$. A faixa de afloramento contorna o espigão de Dracena-Tupi Paulista, próximo à margem do Rio Paraná, em Panorama, penetrando para leste, no vale do Tietê, com espessuras inferiores a $40 \mathrm{~m}$.

Em subsuperfície, sua ocorrência está limitada para oeste de Pirapozinho, Paraguaçu Paulista e Osvaldo Cruz. Volta a aparecer com espessura entre 30 e $40 \mathrm{~m}$ na região centro-ocidental do Estado, tendo sido caracterizado por Brandt Neto (1977) como litofácies de arenitos vermelhos do Membro Inferior da Formação Bauru. Ocorre também na regiåo norte-ocidental do Estado, como em Såo José do Rio Preto, conforme descriçăo de poços nesta região (Arid, 1967; Mezzalira, 1974). Suguio et al. (1977) referem-se à ocorrência nessas regióes de arenitos vermelhos de granulação de fina a média, incluídos na parte inferior da litofácies Araçatuba que, pelas características e posição estratigráfica, correspondem à Formação Santo Anastácio. Localmente, não ocorre essa unidade como em Pereira Barreto, devido possivelmente à existência de altos paleotopográficos da superfície basáltica.

Não ocorre nas regiōes centro-leste e nordeste do Estado e no Triângulo Mineiro. No norte do Paraná, ocorre apenas no testemunho conhecido como Morro dos Três Irmãos em Terra Rica. Ocorre também no leste de Mato Grosso do Sul, sendo sua extensão para oeste desconhecida.

Relaçסes de contato A Formação Santo Anastácio está em contato com as formaçőes Caiuá e Serra Geral. Com a primeira, foi observado em apenas um local, no leito do Rio Santo Anastácio próximo ao Rio Paraná. Verifica-se uma transição textural entre as duas unidades: arenitos da Formação Caiuá estão aparentemente maciços, sendo recobertos por arenitos com características texturais similares, aumentando para cima o teor de matriz e diminuindo a seleção nas sucessivas camadas decimétricas plano-paralelas. A abundante ocorrência de grãos bem arredondados, tipo Caiuá, na parte basal da Formação Santo Anastácio, bem como a mudança brusca no tipo de ambiente e meio de transporte, e ainda a distribuição espacial dessas unidades, indicam uma descontinuidade na sedimentação que, embora possa ser representada por aparente discordância, não tenha envolvido hiato significativo no processo deposicional.

Com a Formaçåo Serra Geral, o contato é discordante erosivo e apresenta relevo suave, embora com desniveis significativos que causam uma redução na espessura ou mesmo ausência local da Formação Santo Anas- 
tácio como em Presidente Prudente, no médio vale do Rio do Peixe ou no vale do Tietê no Salto de Avanhandava.

\section{Idade e ambiente de deposição Na Formação Santo} Anastácio não foram encontrados fósseis, não havendo indicação direta de idade. Soares e Landim (1975), baseados em estudo comparativo da evoluçăo tectônica e sedimentar da parte norte da Bacia do Paraná com a Bacia de Santos, sobre a Plataforma Continental Brasileira, atribuem idade de deposiçáo desses arenitos ao fim do Cretáceo inferior (Aptiano?) tendo em vista que essa sedimentação foi anterior à penecontemporânea com o início do soerguimento no Albiano-Turoniano do arco de Ponta Grossa.

As características litológicas indicam que a deposição dos arenitos dessa unidade deve ter-se realizado dominantemente em canais de meandrantes a retilineos, com pequena profundidade, e em planícies de transbordamento arenosas, refletindo um suprimento lento, uniforme e regular de areia com deficiência na área-fonte de material argiloso. As fácies pelíticas de baixios de inundação, de diques marginais e parte superior de barras em pontal, raramente foram observadas, sugerindo ser muito restritas ou inexistentes. Corpos lenticulares de argila, de preenchimento de canais abandonados, sugerem canais largos e pouco profundos. As fácies de transbordamento parecem constituídas essencialmente de depósitos arenosos de espraiamento. Essas caracteristicas sugerem um modelo fluvial meandrante de a transicional para anastomosado essencialmente psamítico.

\section{FORMAČ̃̃ ADAMANTINA}

rísticas litológicas $e$ seção-tipo A Formação Adamantina é aqui formalmente proposta como denominação a um conjunto de fácies cuja principal característica é a presença de bancos de arenitos de granulação de fina a muito fina, cor de róseo a castanho, portando estratificação cruzada, com espessuras variando entre 2 a $20 \mathrm{~m}$, alternados com bancos de lamitos, siltitos e arenitos lamíticos, de cor castanho-avermelhado a cinza-castanho, maciços ou com acamamento plano-paralelo grosseiro, frequentemente com marcas de onda e microestratificação cruzada.

Essa formação apresenta certas variaçðes regionais, o que tem conduzido diversos pesquisadores a apresentarem denominaçð̄es informais como membro, fácies ou litofácies para esse conjunto. Nesse sentido, Soares et al., 1974, mapearam e descreveram, na regiăo norte-oriental do Estado de São Paulo, um pacote denominado membro inferior da Formação Bauru; Suguio et al. (1977) distinguiram a litofácies São José do Rio Preto e a litofácies Araçatuba, parte síltica de Brandt Neto (1977), na regiåo norte-ocidental desse Estado; Soares et al. (1979) caracterizam para a regiăo sudoeste do Estado as fácies Taciba e Ubirajara. Essas diferentes designaçôes informais justificam-se tendo em vista as características regionais dessa unidade, embora o termo fácies não seja o mais adequado por incluir diversas fácies genéticas.

Como seção-tipo da Formação Adamantina são apresentadas seçðes parciais levantadas entre Adaman- tina e Valparaíso, na estrada de terra que liga essas duas cidades e ao sul de Adamantina, entre o Rio Peixe e Caiabu (Figs. $2 \mathrm{e}$ 3). Verificam-se nessa região as características descritas: repetição cíclica de bancos de arenitos finos com estratificaçăo cruzada a maciços e bancos de siltitos, arenitos, lamíticos, interacamados. Essas constituem as duas principais fácies deposicionais dessa Formação: a de arenitos com estratificação cruzada a maciços, ou fácies de canal, e a de interacamamento de lamitos siltitos, arenitos mui finos, ou fácies de planície de inundação.

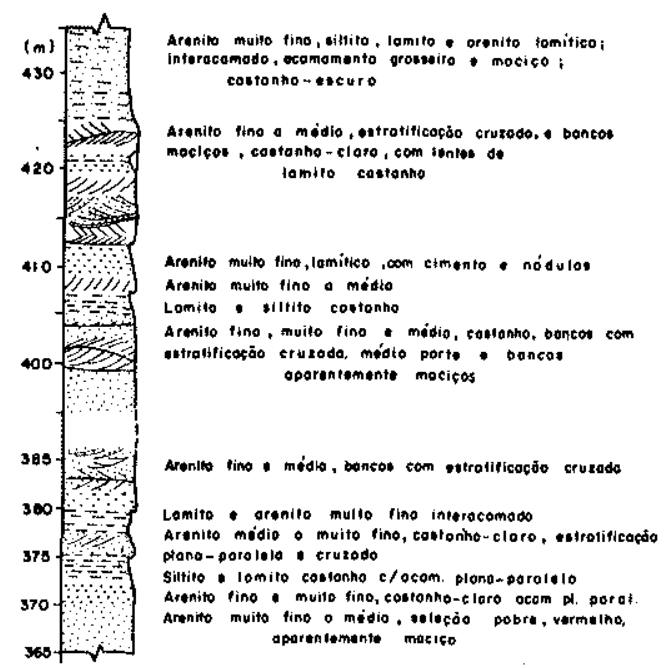

Figura 2 - Seção colunar parcial da Formação Adamantina medida e composta entre Adamantina e Valparaíso (SP).

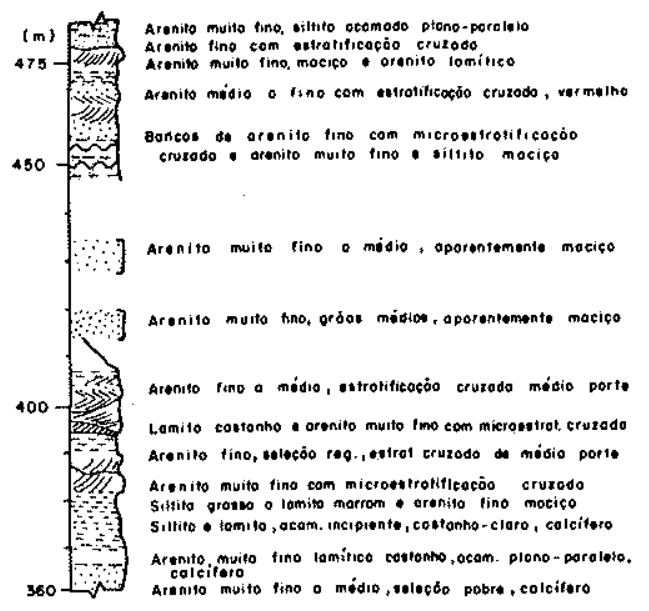

Figura 3 - Seção colunar da Formação Adamantina medida e composta a sul de Marianópolis, entre os $\mathrm{km} 14$ e 18, na estrada para Adamantina (SP).

A litofácies São José do Rio Preto constitui uma variação mais arenosa, com cores acinzentadas e vermelhas, com alguns corpos de conglomerado intraformacional, sendo que a fácies de transbordamento constitui menos de $30 \%$ da espessura da unidade. E freqüente a ocorrência de seixos de argilito da própria unidade. $E$ mais comum que em outras áreas a ocorrência de cimento calcifero, finas camadas de arenito conglomerático e espessos bancos de até $20 \mathrm{~m}$ da fácies de canal. No poço de Bálsamo (Arid, 1967), ocorre desde a superficie até a profundidade de $112 \mathrm{~m}$, onde se situa o contato entre as Formaçð̃es Adamantina e Santo Anastácio (Fig. 4). 
Arid (1967), Coimbra (1976), Suguio (1977) e Brandt Neto (1977) apresentam características sedimentologicas texturais e mineralógicas das rochas da regiåo, as quais se incluem na Formação Adamantina, referidas como litofácies Såo José do Rio Preto ou Araçatuba (parcial) ou ainda membro médio da Formaçăo Bauru (Brandt Neto, 1977) e parcialmente fácies A de Coimbra (1976). O diâmetro médio está entre areia fína e muito fina; a seleção é de boa a muito boa na fração arenosa e de pobre a muito pobre no total. Barcha e Arid (1977) estudaram com mais detalhe as relações entre as propriedades texturais dos sedimentos e suas estruturas sedimentares, caracterizando bem essa unidade na região de São José do Rio Preto.

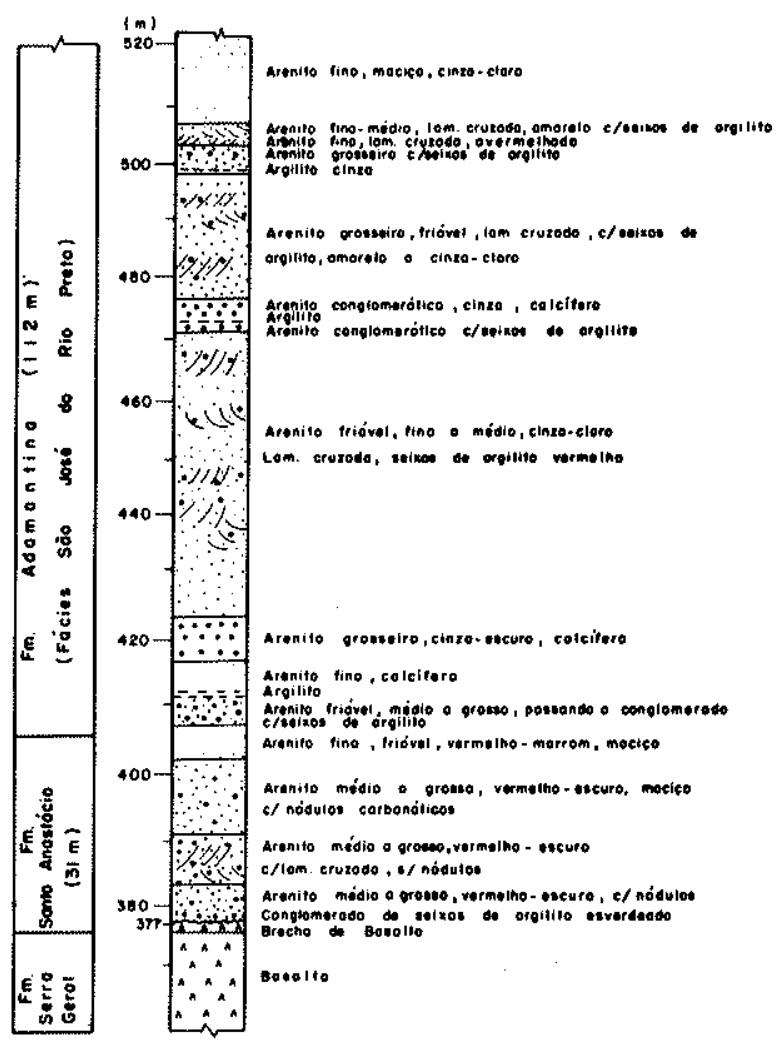

Figura 4 - Perfil litológico do poço de Bálsamo (SP) perfurado pelo IGG, segundo Barcha (1980)

Na regiăo sudoeste do Estado, duas litofácies foram descritas por Soares et al. (1979):

1) Litofácies Taciba (Fig. 5), constituida por uma alternância entre fácies de canal e fácies de transbordamento. A primeira é representada por bancos de 2 a $3 \mathrm{~m}$ de arenitos finos, raramente muito finos e médios, cor rósea a castanho-claro, estratificaça cruzada acanalada e planar-tangencial de pequeno a grande porte, passando a grosseiro, maciço, plano-paralelo, com microestratificado e tubos vermiformes no topo. A segunda representada por bancos de até $10 \mathrm{~m}$ de espessura de lamitos e siltitos castanho-avermelhados, arenitos mui finos, maciços ou com laminaçăo incipiente microcruzada e plano-paralela, raramente leitos calcíferos, marcas de onda, restos fósseis e tubos vermiformes. Corpos tabulares de arenitos finos e brechas intraformacionais, com abundante microestratificação cruzada e interca- lam-se em bancos lamíticos, constituindo depósitos de espraiamento (crevassa). Esses bancos repetem-se ciclicamente com um fraco predominio das fácies de planície de inundação, na regiăo de Presidente Prudente. No poço de Pirapozinho (Mezzalira, 1974) ocorre desde a superficie atingindo a profundidade de $182 \mathrm{~m}$, sobre a Formaçåo Santo Anastácio, constituindo a maior espessura preservada da Formação Adamantina.

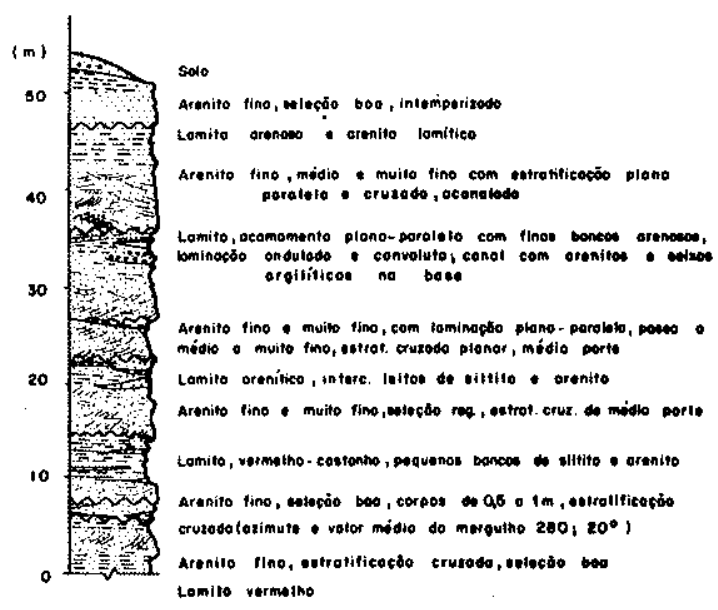

Figura 5 - Seção colunar parcial da litofácies Taciba medida a leste de Anhumas (SP)

2) Litofácies Ubirajara, constituída por uma variaçåo para leste da Formação Santo Anastácio e da litofácies Taciba, caracterizada pela predominância de arenitos de granulação de fina a média, às vezes conglomeráticos, com seixos de quartzito, ágata e basalto; tem cor vermelha ou castanho-avermelhada, estratificação plano-paralela, raramente cruzada de baixo ângulo, seleção pobre, grãos subangulares; raramente ocorrem corpos de lamitos e arenitos lamíticos, descontinuos, com acamamento plano-paralelo. Essa litofácies confunde-se com a Formaçăo Santo Anastácio na área de Paraguaçu Paulista, diferenciando-se desta pela imaturidade textural e mineralógica dos arenitos. No poço do Distrito de Sapezal (Mezzalira, 1974), ocorre sob a Formação Marília a partir de $63 \mathrm{~m}$ (cota de 477) até a profundidade de $120 \mathrm{~m}$, sobre a Formação Santo Anastácio, com as quais a Formação Adamantina está interdigitada.

Ocorrência e espessura A Formação Adamantina é a unidade de maior distribuição em superfície no Estado de São Paulo, aflorando extensivamente: $a$ ) nas regiōes norte (bacia do Rio Turvo) e norte-ocidental (bacia do Rio São José dos Dourados e baixo Rio Tietê), sendo a regiåo de domínio da litofácies São José do Rio Preto com espessura máxima de $160 \mathrm{~m} ; b$ ) nos espigðes entre os rios Tiete e Aguapeí; entre os rios Aguapeí e Peixe, a oeste de Tupa; entre os rios Peixe e Santo Anastácio na regiăo de Presidente Prudente-Presidente Venceslau; entre os rios Santo Anastácio e Paranapanema na regiăo de Mirante do Paranapanema, onde domina a litofácies Taciba, com espessura máxima em torno de $190 \mathrm{~m} ; c)$ no espigão entre os rios do Peixe e Paranapanema, a oeste de Quatá; e médio e alto vale do Rio do Peixe e va- 
le do Rio Turvo, na regiáo de São Pedro do Turvo-Ubirajara, onde ocorre predominantemente a litofácies Ubirajara, com espessura em torno de 100 a $150 \mathrm{~m}$.

Essas espessuras reduzem-se sensivelmente para leste e nordeste, de forma que na escarpa do Planalto $\mathrm{Ba}$ sáltico muitas vezes já não ocorre a Formação Adamantina entre a Formação Serra Geral e a Formação Marília, como em São Carlos e Bebedouro e no sul de Minas Gerais, ou então tem uma ou duas dezenas de metros de espessura, como em Botucatu, Itaqueri e Matão.

Relaçðes de contato $\mathrm{O}$ contato basal da Formaçăo Adamantina, em toda a parte oeste do planalto, é com a Formação Santo Anastácio. E um contato caracterizado por espesso banco da fácies de planície de inundação, constituída por lamitos siltitos e arenitos lamíticos, assentado sobre arenitos de granulação fina e média, maciços, de cor castanho-avermelhado, da Formaçăo Santo Anastácio por meio de uma superfície de brusca mudança litológica. Entretanto a litofácies Ubirajara parece estar interdigitada com a Formação Santo Anastácio. Nas demais regiסes assenta-se discordantemente sobre os basaltos da Formaçăo Serra Geral com conglomerado basal.

As relaçðes de contato entre as litofácies são bastante complexas; entre as litofácies Ubirajara e Taciba ocorre forte interdigitamento, com predomínio daquela fácies na parte basal e superior, no contato com a Formação Marília. Entre estas litofácies e a São José do Rio Preto, verifica-se mudança lateral progressiva nas características, como reduçăo das espessuras dos pacotes lamíticos.

Conteúdo fossilffero A maior parte dos fósseis encontrados no Grupo Bauru situa-se na parte superior da Formaça Adamantina, embora possa ser apenas coincidência pelo fato de os principais centros urbanos, rodovias e ferrovias situarem-se nos espigðes e, aí, ocorrer maior número de escavaçð̌es para obras de engenharia.

Os jazigos fossiliferos apresentados por Mezzalira (1974) situam-se na quase totalidade nesta Formação, exceto os da região de Marília e Piratininga, e regiåo nordeste do Estado que se localizam na parte inferior da sobrejacente Formação Marília.

Os principais grupos paleontológicos dessa unidade são: moluscos, conchostráceos, peixes, quelônios, crocodilídeos e dinossauros theropodas e saurópodas, além de algas charáceas e outros restos vegetais (Arid, 1967; Mezzalira, 1974).

Idade e ambiente de deposiçao $\mathrm{O}$ conteúdo paleontológico, de uma maneira geral, fornece pouca informaçăo cronoestratigráfica; entretanto a presença de um titanossaurídeo permitiu a Huene (1933, in Price, 1950), por correlação com fósseis similares em sedimentos da Patagônia, atribuir idade Senoniana do Cretáceo Superior a essa Formação.

Soares e Landim (1975), por comparação com a evolução da Bacia de Santos e devido à contemporaneidade com rochas alcalinas da Formaçăo sobrejacente, na região do Triângulo Mineiro, atribuíram idade do Cretáceo Médio, Cenomaniano a Santoniano ao intervalo correspondente à Formação Adamantina. Essa am- plitude de idade está coerente com a idade Senoniana atribuída aos fósseis, pois estes se encontram na parte superior da Formaçăo. Deve-se considerar também que a seção preservada da Formação Adamantina é parcialmente contemporânea à Formação Marília, tendo em vista o interdigitamento entre essas unidades na regiao norte-nordeste do Estado, conforme foi verificado por Soares et al. (1973).

Considerando-se as diferentes fácies deposicionais, conclui-se que a Formação Adamantina foi depositada em um extenso sistema fluvial meandrante dominantemente pelítico a sul, gradando para psamítico a leste $\mathrm{e}$ norte, e parcialmente nessas regióes com transição para anastomosado. Os arenitos com estratificaçăo cruzada passando a maciços e plano-paralelos representam depósitos em barras de pontal ou transversais realizados nos canais. Os lamitos e siltitos foram depositados nas planícies de inundaçăo em baixios, várzeas e lagoas, e os arenitos ricos em microestratificaçăo cruzada por rompimento de diques marginais e espraiamento sobre a planície.

FORMAÇÃO MARÍLIA Definição, caracteristicas litológicas e seçäo-tipo Define-se neste trabalho a Formação Marilia como uma unidade composta por arenitos de grosseiros a conglomeráticos, com grãos angulosos, teor de matriz variável, seleção pobre, ricos em feldspatos, minerais pesados e minerais instáveis; ocorrem em bancos com espessura média entre 1 e $2 \mathrm{~m}$, maciços ou com acamamento incipiente subparalelo e descontínuo, raramente apresentando estratificação cruzada de médio porte, com seixos concentrados nos stratos cruzados; raras camadas descontínuas de lamitos vermelhos e calcário são encontradas.

A designação Formação Marília foi utilizada por Almeida e Barbosa (1953) para um conjunto similar de litologias, tendo sido considerada como unidade superior do Grupo Bauru; ao mesmo tempo nomearam Formação Itaqueri para a associação litológica com as características primárias similares, porém destituída de cimento calcífero, aflorante na Serra de Itaqueri e São Carlos. Essa divisão de Almeida e Barbosa (1953) foi considerada inadequada (Freitas, 1955; Mezzalira, 1974), tendo sido posteriormente abandonada. Mapeamentos executados posteriormente mostraram que os arenitos grosseiros conglomeráticos de Itaqueri, São Carlos e Matão constituem uma fácies pouco calcífera, às vezes com cimento silicoso, que passa lateralmente, no sentido oeste, para a fácies de arenitos calco-conglomeráticos da Formação Marília, como foi verificado por Soares et al: (1973). No presente trabalho, esses sedimentos são referidos como litofácies Itaqueri.

A seção-tipo da Formação Marília localiza-se na escarpa sul do Planalto de Marília, entre o Rio do Peixe e a cidade de Marilia (Fig. 6). Outra seçãa de referência apresentada é a de Monte Alto na escarpa a sul desta cidade (Fig. 7).

Os arenitos dessa Formação distinguem-se facilmente das outras unidades pela granulação dominantemente grosseira, níveis de conglomerados com seixos de quartzo, opala, basalto e argilito, e o caráter maciço dos bancos. São raros os corpos, de um modo geral lenticulares, de lamitos ou arenitos lamíticos no topo dos ban- 


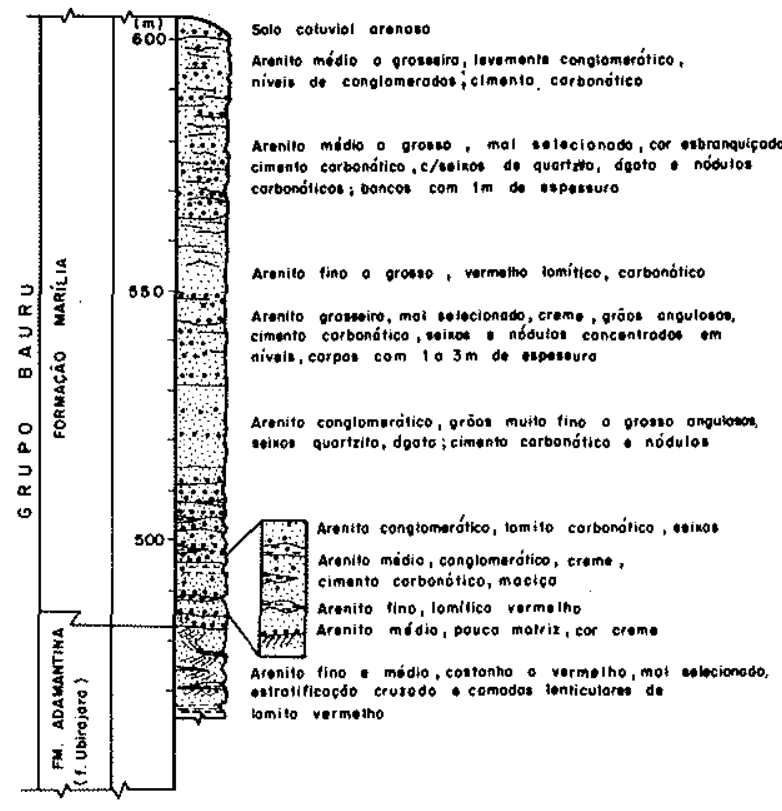

Figura 6 - Seção colunar parcial da Formação Marília medida e composta entre Marília e o Rio do Peixe na rodovia Marilia-Assis (SP)

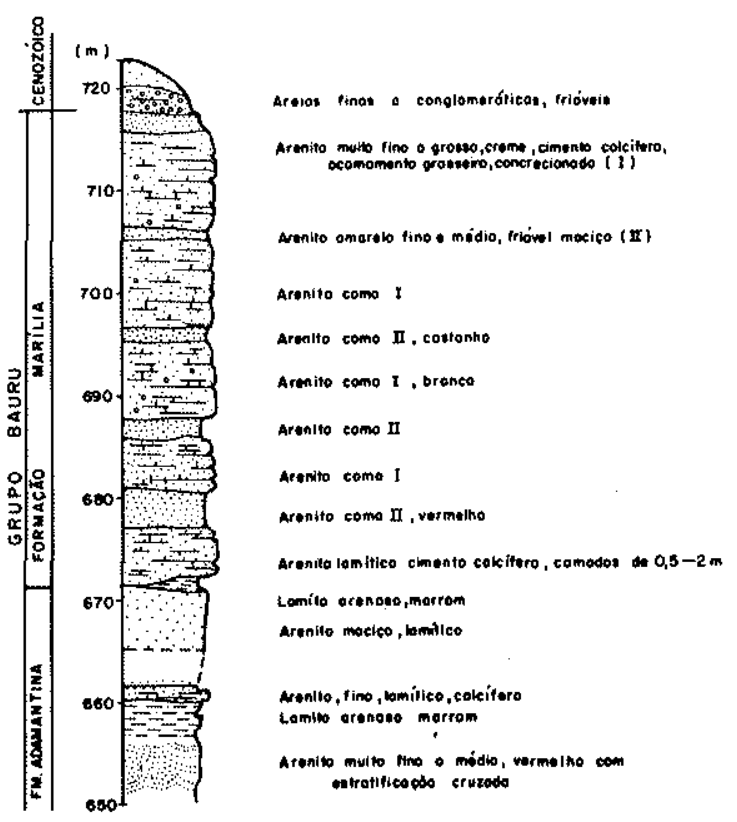

Figura 7 - Seça colunar parcial do Grupo Bauru na região de Monte Alto, nordeste do Estado de São Paulo

cos. Ocorre frequentemente um afinamento da granulometria, com arenitos finos lamíticos vermelhos e maciços, lembrando regolito fóssil, no topo dos bancos. A presença em abundância de nódulos carbonáticos irregulares, ora esparsos nos arenitos, ora concentrados em niveis, epigenéticos, ou ainda em bolsðes ou lentes por retrabalhamento, é uma característica da unidade. Os arenitos nodulares e conglomeráticos dos contrafortes dos espigðes de Echaporã, Marília-Tupã, Taquaritin- ga, Monte Alto e Monte Azul encontram-se fortemente cimentados e com cores creme ou esbranquiçadas. Soares e Landim (1975) caracterizaram esta unidade como membro superior da Formação Bauru. Incluíram neste membro superior as fácies de arenitos tufáceos, designada por Hasui (1967), de Formação Uberaba e aflorantes no Triângulo Mineiro.

Em alguns locais são encontradas linhas de seixo que lembram lençóis rudáceos residuais. Também algumas camadas de calcário, branco, micrítico, às vezes com grãos e seixos de quartzo, são encontradas nessa unidade, especialmente na transição com a Formação Adamantina, ou ainda concentraçóes de seixos no topo do banco, representando um aumento de granulometria de baixo para cima, como no corte do cruzamento da Rodovia Marechal Rondon com o leito da Fepasa, em Botucatu. Essa granulação crescente para cima é uma característica da unidade como um todo, predominando a presença de conglomerados próximo ao topo.

Suguio et al. (1977) e Soares et al. (1979) apresentaram características granulométricas da unidade, com a designaçăo de litofácies Marília. Soares et al. (1973) e Amaral (1977) apresentaram características de fotointerpretação a partir de fotos aéreas (Membro Superior da Formaça Bauru) e de imagens de satélite (Litofácies B.3), respectivamente.

Ocorrência e espessura A Formação Marilia ocorre extensivamente na parte leste do Planalto Ocidental do Estado de Såo Paulo, prolongando-se para oeste nos espigð̋es entre os principais rios. Entre os rios Paranapanema e Peixe, ocorre no planalto de Echapora, estendendo-se até Quatá. Entre os rios do Peixe e Aguapeí, prolonga-se até as proximidades de Tupå. Na regiăo norte-nordeste ocorre entre Matão e Taquaritinga até Catanduva e, para norte, em Monte Alto até Bebedouro. No nordeste do Estado, no planalto de Franca, e no centro-leste, na Serra de Itaqueri e planalto de São Carlos, ocorre a litofácies Itaqueri, constituida de arenitos de granulação de fina a grosseira e conglomerática, mal selecionados, com gråos angulosos, maciços, com cimento silicoso possivelmente substituindo o cimento carbonático.

A espessura da Formaçåo Marilia atinge o máximo na cidade homónima, com $160 \mathrm{~m}$, recoberta por sedimentos cenozóicos, da mesma forma que em Monte Alto, com cerca de $150 \mathrm{~m}$. Reduz sensivelmente para oeste por erosão durante o aplainamento do ciclo Sul-Americano e ciclos erosivos posteriores.

Relaçós de contato A Formação Marília está em contato principalmente com a Formaçåo Adamantina, com as fácies Ubirajara, no centro do Estado, e São José do Rio Preto no norte-nordeste. A transição se faz por meio de sucessivas superfícies erosivas, ora com mudança brusca de litologia e conglomerado basal, ora com recorrência das litologias de uma unidade na outra, indicando interdigitamento. A leste, maior é a aparência discordante do contato; são encontrados leitos de conglomerado basal com seixos de arenito, argilito, basalto, quartzo e ágata, e mudança brusca da litofácies Ubirajara para os arenitos grosseiros carbonáticos da Formaça Marília. Sobre a Formaçåo Serra Geral é fre. 
quiente o contato nas ocorrências mais a leste, como em Itaqueri, Săo Carlos e Franca. O contato é por discordância erosiva, com mais de $1 \mathrm{~m}$ de conglomerado com abundantes seixos de basalto, quartzito, arenito e ágata, acima do qual ocorrem arenitos grosseiros e conglomeráticos da fácies Itaqueri. Localmente, sobre estruturas dômicas pré-Bauru, o contato é uma discordância angular, podendo assentar-se sobre o Botucatu, Pirambóia ou mesmo sills de diabásio.

$\mathrm{Na}$ regizo de Monte Alto, Bebedouro e Olímpia, a Formação Marilia é claramente interdigitada com a fá. cies Săo José do Rio Preto, tornando difícil a separaçăo devido a presença de corpos de arenitos calco-conglomeráticos que desaparecem para sul e oeste (Soares et al., 1973) dentro da Formaçăo Adamantina.

láade e ambiente de deposiço A idade do início de sedimentação da Formaçăo Marília pode ser estabelecida pela presença nas partes inferiores da associação faunística similar à da Formaça Adamantina, como os restos encontrados em Colina (peixes, crocodilídeos, sauropoda e theropoda, e quelónios), ostracódios em Såo Carlos, restos de dinossáurios em Taquaritinga e Fernando Prestes, etc. (Mezzalira, 1974). Nesses achados incluem-se restos de titanossaurídeos encontrados en Colina, na área de ocorrência da Formaçåo Marília, aos quais foi atribuida a idade Senoniana. A sedimentacăo dessa Formação foi contemporânea com o soerguimento da parte norte da Serra do Mar e do arco da Canastra (Soares e Landim, 1975) ou do Alto Parnaíba (Saad ef al., 1971), e com o vulcanismo associado com idades entre 80 e 60 milhoes de anos. Dessa forma, a sedimentação da Formaçăo Marília verificou-se entre o Santoniano e o Maestrichtiano.

As características texturais, mineralógicas, as estruturas sedinientares e a geometria dos corpos permitem interpretar a sedimentacão dos arenitos conglomeráticos da Formaça Marília como sendo por correntes de alta energia, com transporte fora de canais em extensos lençós de escoamento, com deposição rápida, impedindo a formaça de estruturas. Esses corpos sedimentados ficavam expostos durante longo tempo, permitindo que processos pedogenéticos produzissem o concrecionamento com formaçăo das estruturas nodulares. O escoamento de novas torrentes retrabalhava esses sedimentos transportando os nodulos juntamente com seixos trazidos da área-fonte e redepositando-os. A ausência de matriz nos arenitos de deposição rápida sugere clima árido onde não se formariam solos argilosos. A ocorrência de depósitos do tipo calibre descritos por Suguio et al. (1975) corrobora a interpretação.
Tais condições de sedimentação por torrentes em lençol são característicos de leques aluviais, onde a sucessiva mudança dos lobos deposicionais com a subsidência da bacia produziu a coalescência e o empilhamento vertical dos diversos corpos. Localmente, entre os leques formaram baixadas de restritos afluxo de clásticos grosseiros, produzindo depósitos lamíticos ou finas camadas de calcário.

A granulometria crescente para cima indica que a sedimentação das litologias preservadas na Formação Marília foi realizada cada vez mais próxima das cabeceiras desses leques, sugerindo incremento na taxa de soerguimento de arcos marginais.

\section{ESBOÇO DE EVOLUÇÃO PALEOGEOGRÁFICA} DO GRUPO BAURU Encerrado o vulcanismo ba. sáltico no eo-Cretáceo, a Bacia do Paraná foi submetida a um rápido ciclo erosivo. As condiçðes climáticas poderiam ter favorecido o desenvolvimento de um deserto com acumulação de areia eólica em grandes dunas, formada por ventos soprando de leste, na zona subsidente sobre a regia do arco de Ponta Grossa. Com o resfriamento regional, o deserto foi progressivamente sendo substituido por um sistema fluvial, migrando de norte para sul, e com direça preferencial de escoamento para oeste-sudoeste, com canais anastomosados e excesso de carga arenosa, parcialmente derivada das areias eólicas.

No início do Cretáceo médio, o centro deposicional migrou do noroeste do Paraná para a oeste do Estado de Săo Paulo; o sistema anastomosado foi substituído por um imenso sistema fluvial meandrante (fácies Taciba e São José do Rio Preto) e retraiu-se para as faixas marginais (Fácies Ubirajara). O clima passou a úmido com abundante deposiçáb pelítica, sob condiçóes de quiescência tectônica.

No fim do Cretáceo Médio, as faixas marginais evoluíram para leques aluviais, com o clima tornando-se novamente árido. O soerguimento crescente dos arcos da Canastra e Serra do Mar, acompanhado de vulcanismo alcalino, produzia uma progradação dos leques sobre o sistema meandrante periférico com posterior assoreamento da bacia.

No fim do Cretáceo ou início do Terciário, inicia-se novo ciclo erosivo na Bacia, culminando com o aplainamento Sul-Americano e posterior recorrência de novos ciclos erosivos cenozóicos.

Agradecimentos Agradecimentos são prestados ao Departamento de Águas e Energia Elétrica do Estado de São Paulo por possibilitar a execução do presente trabalho.

\section{BIBLIOGRAFIA}

ALMEIOA, F.F.M. e BARBOSA, O. - 1953 - Geologia das quadriculas de Piracicabs e Rio Claro, Est. de S. Paulo. DNPM, DGM, B. 143, 96 pp., Rio de Janeiro.

AMARAL, G. - 1977 - Padiós fotogeologicos das litofacies da Formacta Bauru no Est. de S. Paulo, como observados em imagens Landsat. Anais do I Simpósio de Geol. Rrg. do Núcteo de Slo Paulo. SBG, pp. 439.449.

ARID, F.M. - 1967 - A Formaçăo Bauru na regito norte-ocidental do Estado de Stao Paulo. Bol, Fac. Fij. Cienc. Letr. S. J. Rio Preto, Geol. n: 1: 126 pp.

ARID, F.M. e VIZOTTO, L.D. - 1971 - Tracos paleogeográficos e paleobiológicos do Cretáceo Superior da regito norte ocidental do Estado de Sáo Pauto. Cienc. Cult. 23(3): 229.236.
BARBOSA, O., BRAUN, O.P.G., DYER, R.C. C CUNHA, C.A.B.R. - 1970 - Geologis do triangulo minejro. DNPM, DFPM, Bol. 136, 140 pp.

BARCHA, S.F. - 1980 - Aspectos geologicos e provincias hidrogeologicas da Formaço Bauru na regiao norte-ocidental do Estado de Săo Paulo. Tese de Livre-Docencia apresentada ao I. BILCE, UNESP, Campus de S. J. Rio Preto (inédito).

BARCHA, S.F. e ARID, F.M. - 1977 - Parametros granulometricos de estruturas sedimentares $\mathrm{e}$ interpretaça do ambiente dinßmico da Formaça Bauru (Kn). Naturalia 3: 15-34.

BRANDT NETO, M. - 1974 - Estratigrafia da Formaça Bauru na regiăo do baixo Tietê. Dissertaçao Mestrado. Inst. de Geoc., USP (inédita). 
COIMBRA, A.M. - 1976 - Ar enitos da Formaşa Bauru - estudo de áreasfontes. Dissert. Mestrado, Inst. de Geoc., USP, 2 vols.

FREITAS, R.O. - 1955 - Sedimentaçró, estratigrafia e tectónica da Strie Bauru, Sao Paulo, F.F.C.L. da USP, Bol. 194, Geol. 14, 179 pp.

CONZAGA DE CAMPOS, L.F. - 1905 - Reconhecimento da zona com preendida entre Bauru e Itapira, E.F. Noroeste do Brasil, Tip. Ideal, $40 \mathrm{pp}$ HASUI, Y. - 1968 - A Formasto Uberaba. Anais do XXVII Congr. Bras. de Geologia, pp. 167-169.

HUENE, F. - 1933 - Ein Versuch Stammesgeschichte der Krokodile: Centralb. 1. Min. Jargh., 1933, Abt B. 11: 577-585.

LANDIM, P.M.B. SOARES, P.C. - 1976 - Estratigrafia da Formaça Caiuá. Anais do XXIX Congr. Bras. de Geol., vol. 2, pp. 195-206.

MEZZALIRA, S. - 1974 - Contribuiça ao conhecimento da estratigrafia e paleontologia do Arenito Baurt. Inst. Geogr. e Geol., Bol. n? 51, 163 pp.

PRICE, L.I. - 1950 - Os crocodilideos da fauna da Formaça Bauru do Cret́́ceo terrestre do Brasil Meridional. An. Acad. Bras. Cienc, 22(4): 473-490. PRICE, L.I. - 1953 - Os quelónios da Formaçăo Bauru, cretáceo terrestre do Brasil Meridional. D.N.P.M., D.G.M., Bol. n? 147.

SAAD, J.H.G., CARDOSO, R.N. e COSTA, M.I. - 1971 - Formaçひes cre tácicas em Minas Gerais: uma revisto. Rev, Bras. Geociencias 1(1): 2-21.

SCHNEIDER, R.L., MOHLMANN, H., TOMMAZI, E., MEDEIROS, R.A. DAEMON, R.F. C NOGUEIRA, A.A. - 1964 - Revisao estratigráfica da Bacia do Paraná. An. XXVIII Congr. Bras. Geol, vol. 1, 41-65.

SOARES, P.C. e LANDIM, P.M.B. - 1975 - Comparison bet ween the tectonic evolution of the intracratonic and marginal basins in South Brazil. An. Acad. Bras. Cienc., vol. 48 (supl.): 313-324.

SOARES, P.C., LANDIM, P.M.B., FULFARO, V.J. e SOBREIRO NETO, A. F. - 1979 - Ensaio de caracterizacto estratigráfica do cretáceo no Estado de Sto Paulo. Resumos do 20. Simpósio Regional de Geologia, Núcleo de Sllo Paulo, S.B.G., pp. 30-31.
SOARES, P.C., LANDIM, P.M.B., FÚLFARO, V.J., AMARAL, G., SUGUIO, K., COIMBRA, A.M., SOBREIRO NETO, A.F., GIANCURSI, F. CORREA, W.A.G. e C.ASTRO, C.G.J. - 1979 - Geologia da regito Sudoeste do Estado de Sto Paulo. Atas do 2: Simpósio Regional de Geologia, Núcleo Sao Paulo, S.B.G., vol. 2, pp. 307.319.

SOARES, P.C.. SINELll, O., PENALVA, F., WERNICK, E., SOUZA, A. CASTRO, P.R.M. - 1973 - Geologia do Nordeste do Est8do de Sťo Paulo. An. XXVlI Congr. Bras. Geologia, vol. 1, pp. $209-229$.

STEIN, D.P., MELO, M.S., BISTRICHI, C.A., ALMEIDA, M.A., HASUY, Y., PONCANO, W.L. c ALMEIDA, F.F.M. - 1979 - Gcologia de parie dos vales dos rios Paraná e Paranapanema. Atas do 2. Simp. Reg. Geologia, Núcleo Săo Paulo, S.B.G., vol. 2, pp. 291.306.

SUAREZ, 3.M. - 1973 - Contribuiçăo à Geologia do Exıremo Oeste do Estado de Săo Paulo. Tese de Doutoramento apresentada a Fac. Fil. Ciênc, Letr, , Presidente Prudente (inedita).

SUGUIO, K. - 1973 - Formaçăo Bauru: calcários c sedimentos detriticos associados. Tese de Livre-Docência. Inst. de Geoc. da USP, 2 rols., $236 \mathrm{pp}$.

SUGUIO, K., BERENHOLC, M. e SALATI, E. - 1975 - Composisto química $\mathrm{c}$ isotópica dos calcários e ambiente de sedimentasto da Formaça Bau. ru. Bol, IG, Inst. Geociênc., USP, no: 6, pp. 55-75.

SUOUIO, K., FULFARO, V.J., AMARAL, G. e GUIDORZI, L. - 1977 Comportamentos estratigráficos e estrutural da Formaçăo Bauru nas regioes administrativas 7 (Bauru), 8 (Sao Jost do Rio Preto) e 9 (Araçatuba) no Est 8do de Săo Paulo. An. do 1 Simp. de Geol. Reg., Núcleo de Săo Paulo, SBO, pp. 231-247.

WASHBURNE, C.W. - 1930 - Petroleum Geology of the State of Săo Paulo. Inst. Geogr. Geologico n? 22. 